\title{
Big Data-Driven Approach for Health Inequalities in Foreign Patients with Injuries Visiting Emergency Rooms
}

\author{
Jin Young Kang ${ }^{1 *}$, Jinhee Kwon ${ }^{2 *}$, Chang Hwan Sohn ${ }^{1}$, Youn-Jung Kim ${ }^{1}$, Hyo Won Lim³ \\ Seung Joon Lee ${ }^{4}$, Won Young Kim ${ }^{1}$, Namkug Kim ${ }^{5}$, Dong-Woo Seo ${ }^{1,6}$ \\ 'Department of Emergency Medicine, Asan Medical Center, University of Ulsan College of Medicine, Seoul, Korea \\ 'Department of Biomedical Engineering, Asan Medical Institute of Convergence Science and Technology, Asan Medical Center, University of Ulsan College of \\ Medicine, Seoul, Korea \\ ${ }^{3}$ Asan Medical Center, University of Ulsan College of Medicine, Seoul, Korea \\ ${ }^{4}$ National Emergency Medical Center, Seoul, Korea \\ ${ }^{5}$ Department of Convergence Medicine, Asan Medical Center, University of Ulsan College of Medicine, Seoul, Korea \\ ${ }^{6}$ UCSD Health Department of Biomedical Informatics, University of California San Diego, La Jolla, CA, USA
}

Objectives: Foreign patients are more likely to receive inappropriate health service in the emergency room. This study aimed to investigate whether there is health inequality between foreigners and natives who visited emergency rooms with injuries and to examine its causes. Methods: We analyzed clinical data from the National Emergency Department Information System database associated with patients of all age groups visiting the emergency room from 2013 to 2015. We analyzed data regarding mortality, intensive care unit admission, emergency operation, severity, area, and transfer ratio. Results: A total of 4,464,603 cases of injured patients were included, of whom 67,683 were foreign. Injury cases per 100,000 population per year were $2,960.5$ for native patients and 1,659.8 for foreign patients. Foreigners were more likely to have no insurance ( $3.1 \%$ vs. $32.0 \%, p<0.001$ ). Serious outcomes (intensive care unit admission, emergency operation, or death) were more frequent among foreigners. In rural areas, the difference between serious outcomes for foreigners compared to natives was greater $(3.7 \%$ for natives vs. $5.0 \%$ for foreigners, $p<0.001$ ). The adjusted odds ratio for serious outcomes for foreign nationals was 1.412 (95\% confidence interval [CI], 1.336-1.492), and that for lack of insurance was 1.354 (95\% CI, 1.314-1.394). Conclusions: Injured foreigners might more frequently suffer serious outcomes, and health inequality was greater in rural areas than in urban areas. Foreign nationality itself and lack of insurance could adversely affect medical outcomes.

Keywords: Wounds and Injuries, Healthcare Disparities, Emigrants and Immigrants

Submitted: August 12, 2019

Revised: November 4, 2019

Accepted: January 17, 2020

\section{Introduction}

\section{Corresponding Author}

Dong-Woo Seo

UCSD Health Department of Biomedical Informatics, University of California San Diego, La Jolla, CA, USA. Tel: +1-619-214-5262, E-mail: d2seo@ucsd.edu (https://orcid.org/0000-0001-8104-0247)

*These two authors contributed equally to this work.

This is an Open Access article distributed under the terms of the Creative Commons Attribution Non-Commercial License (http://creativecommons.org/licenses/bync/4.0/) which permits unrestricted non-commercial use, distribution, and reproduction in any medium, provided the original work is properly cited.

(c) 2020 The Korean Society of Medical Informatics
Immigration around the world is constantly on the rise [1]. In 2000, the worldwide number of immigrants was 150 million, and it grew to 214 million in 2010. It is expected to increase to 405 million by 2050 [1,2]. Accompanying rapid economic development, the number of immigrants is increasing in East Asia and South Korea, where rapid aging is taking place [3]. The number of registered foreigners in South Korea increased from 244,172 ( $0.5 \%$ of population) in 2000 to $1,413,758$ (2.8\% of population) by 2016 [3]. 
In many countries with a long history of immigration, there is much evidence that the morbidity and mortality of foreigners are higher than those of the native population [4-6]. This pattern varies according to age, sex, cause, and environment [7-9]. There is also evidence that injuries are more prevalent in immigrants [7-9]. The latter tend to have low socioeconomic status and be engaged in unskilled, high-risk jobs $[4,10,11]$. Medical access is restricted due to language barriers, and stress and discrimination often lead to crime. These factors are known to cause high mortality in immigrants.

However, previous studies had limitations because they used national data or insurance registration based only on patients enrolled in the registry $[6,7,10,11]$. Foreigners tend to be socially weak and are more likely to be underrepresented in such registries. Previous studies may have underestimated real-world data on the injuries of foreigners. Injuries are more likely to be dealt with in emergency departments (EDs) because they tend to be more time-dependent than medical illnesses, such as cancer. Given these characteristics, analyzing the patient data of emergency rooms will provide more realistic estimates of health inequalities.

Unlike in developed countries with a long history of immigration, such studies are rare in East Asian countries. The purpose of this study was to investigate whether there is a wide range of health inequalities between foreigners and natives who visited emergency rooms with injuries and to examine its potential causes.

\section{Methods}

\section{Study Population}

This study used the National Emergency Department Information System (NEDIS), which comprises data prospectively collected by the National Emergency Medical Center [12]. The NEDIS was created in 2003, and 408 EDs (98.8\% of the EDs throughout South Korea) are included [12]. Patient information is transferred automatically in real-time from each ED to the National Emergency Medical Center [12]. Population data (denominator determination) were obtained from the Korean Statistical Information Office's 2015 census [3]. The Institutional Review Board of Asan Medical Center approved the study and waived the requirement for informed consent due to its retrospective nature and the use of an anonymized dataset (IRB No. 2017-0998).

\section{Data Sources}

The study period was from January 1, 2013, to December
31,2015 . We collected 4,464,603 cases registered as injuries in the NEDIS. The registry includes all age groups and covers both domestic and foreign patients treated in South Korea. Foreigners are defined in this study as all persons who do not have Korean nationality. The NEDIS includes both registered-defined as persons who have registered as foreign residents in Korea-and unregistered foreigners because foreigners can apply to an emergency room regardless of whether they are registered or not. A person with South Korean nationality must join the National Health Insurance scheme, and persons with foreign citizenship can participate if they have lived for 6 months or more in South Korea. A foreigner can have private insurance.

\section{Study Outcomes}

Need for an emergency operation, admission to the intensive care unit (ICU), or death during ED were defined as serious outcomes, and this was our primary outcome. Demographic data collected from the NEDIS dataset included age, sex, injury mechanism, date, intention (self-injury or violence by others), insurance state, and geographic location of the ED. Clinical data included determination of emergency symptoms by the national health insurance provider, blood pressure and consciousness level at ED presentation, disposition of injured patients (discharge, transfer to other hospitals, admission to general ward or ICU, emergency operation, and death), and information about the timing of hospitalization and discharge. Consciousness at ED presentation was measured using the AVPU scale (alert, verbal, pain, unresponsive), and decreased consciousness was defined as all states except alert. Low blood pressure was defined as an initial systolic blood pressure of 90 or less. An administrative area with a population density of 1,000 person per square kilometer or more was defined as an urban area. Emergency medical service (EMS) providers in South Korea transfer patients to the nearest ED. We assumed that the location at which the injury occurred was in the same region as the emergency room.

\section{Statistical Analysis}

Continuous variables were expressed as means with standard deviation or medians with interquartile range (IQR). Normality of distribution was examined by the KolmogorovSmirnov test. Categorical variables were reported as numbers and percentages. The Mann-Whitney $U$ test was used to compare the values of continuous variables. The chi-square test was applied for categorical variables. Multivariable logistic regression analysis was performed for serious outcomes. 
The results of the logistic regression analysis are presented as odds ratios (OR) and $95 \%$ confidence intervals (CI). For all the analyses, a two-sided $p$-value of $<0.05$ was considered to indicate a statistically significant difference. Statistical analyses were performed by using $\mathrm{R}$ version 3.4.2 (R Foundation for Statistical Computing, Vienna, Austria).

\section{Results}

Injury cases per 100,000 population per year were $2,960.5$ for native patients and 1,659.8 for foreign patients (Table 1). The average age of foreigners (35.5 years) was higher than that of natives (34.2 years). In both groups, the frequency of injury in males was higher $(65.7 \%$ vs. $59.8 \%, p<0.001)$. The per- centages of intentional injuries were not significantly different for the two groups $(1.7 \%$ vs. $1.7 \%, p=0.066)$. Foreigners were more likely to have no insurance $(32.0 \%$ vs. $3.1 \%, p<$ 0.001 ). In both groups, injuries were more common in urban areas.

There was a difference between the age distributions of native and foreign patients (Figure 1A). In the case of Koreans, children under the age of 5 were the most common. In the case of foreigners, a bimodal pattern was observed, with the age groups between 20 and 30 being the most common. Regarding the injury mechanism, foreign patients presented with more violence, penetrating injury, burns, and machinerelated injuries $(p<0.001)$ (Table 1, Figure 1B).

As seen in Table 2, serious outcomes (ICU admission,

Table 1. Characteristics of injury cases in NEDIS data

\begin{tabular}{|c|c|c|c|}
\hline & $\begin{array}{l}\text { Native patients } \\
(n=4,396,920)\end{array}$ & $\begin{array}{l}\text { Foreign patients } \\
(\mathrm{n}=67,683)\end{array}$ & $p$-value \\
\hline Injury cases per 100,000 population per year & $2,960.5$ & $1,659.8$ & \\
\hline Age (yr) & $34.2 \pm 23.5$ & $35.5 \pm 16.5$ & $<0.001$ \\
\hline $0-9$ & $949,429(21.6)$ & $5,547(8.2)$ & \\
\hline $10-19$ & $456,993(10.4)$ & $2,163(3.2)$ & \\
\hline $20-29$ & $546,897(12.4)$ & $18,267(27.0)$ & \\
\hline $30-39$ & $578,993(13.2)$ & $15,530(22.9)$ & \\
\hline $40-49$ & $591,570(13.5)$ & $11,534(17.0)$ & \\
\hline $50-59$ & $592,190(13.5)$ & $9,699(14.3)$ & \\
\hline $60-69$ & $318,680(7.2)$ & $3,786(5.6)$ & \\
\hline$\geq 70$ & $362,168(8.2)$ & $1,157(1.7)$ & \\
\hline Male sex & $2,628,793(59.8)$ & $44,451(65.7)$ & $<0.001$ \\
\hline Injury vector & & & $<0.001$ \\
\hline Fall & $1,060,987(24.1)$ & $12,856(19.0)$ & \\
\hline Violence & $863,721(19.6)$ & $13,659(20.2)$ & \\
\hline Traffic accident & $760,077(17.3)$ & $9,924(14.7)$ & \\
\hline Penetrating & $623,449(14.2)$ & $12,045(17.8)$ & \\
\hline Burn & $140,380(3.2)$ & $2,425(3.6)$ & \\
\hline Poisoning & $105,256(2.4)$ & $1,314(1.9)$ & \\
\hline Machine related & $42,408(1.0)$ & $2,436(3.6)$ & \\
\hline Hanging & $11,539(0.3)$ & $82(0.1)$ & \\
\hline Drowning & $3,600(0.1)$ & $61(0.1)$ & \\
\hline Unknown & $785,198(17.9)$ & $12,875(19.0)$ & \\
\hline Intentional injury & $76,724(1.7)$ & $1,118(1.7)$ & 0.066 \\
\hline No insurance & $136,028(3.1)$ & $21,686(32.0)$ & $<0.001$ \\
\hline Urban area & $3,105,739(70.6)$ & $52,222(77.2)$ & $<0.001$ \\
\hline
\end{tabular}

Values are presented as mean \pm standard deviation or number (\%).

NEDIS: National Emergency Department Information System. 

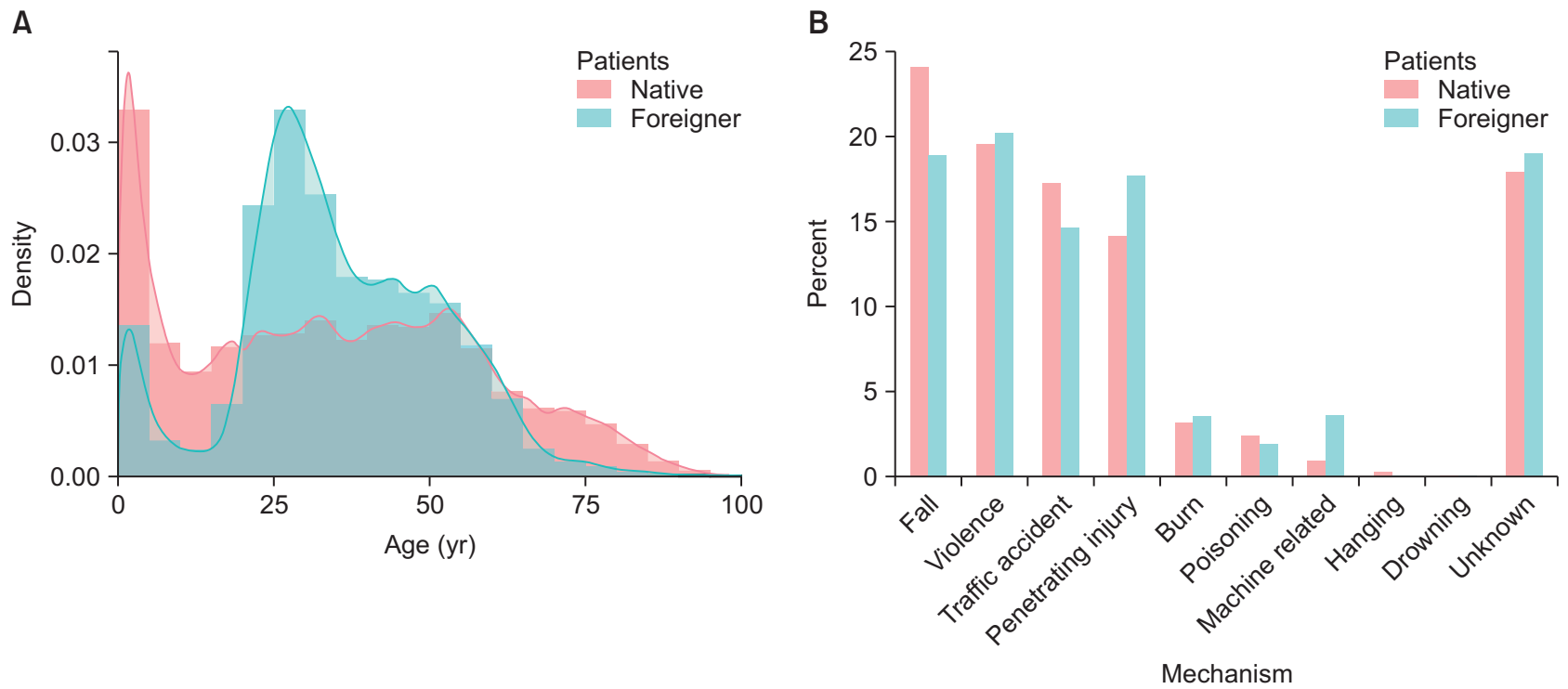

Figure 1. Characteristics of injuries in native and foreign patients: (A) normalized histogram of age distribution and (B) injury mechanism.

emergency operation, or death) were more frequent among foreigners than natives $(3.8 \%$ vs. $3.1 \%, p<0.001)$. In rural areas, the difference in serious outcomes was greater for foreigners (5.0\% vs. $3.7 \%, p<0.001)$. Decreased consciousness at ED presentation was more frequent among foreigners than natives $(2.7 \%$ vs. $2.4 \%, p<0.001)$. However, low blood pressure at ED presentation was more frequent among natives than foreigners $(2.8 \%$ vs. $1.8 \%, p<0.001)$. Cases of transfer to other hospitals were also more frequent among foreigners than natives ( $3.1 \%$ vs. $2.8 \%, p<0.001)$. Admission to ICU $(1.7 \%$ vs. $1.6 \%, p<0.001)$ and need for emergency operation $(1.7 \%$ vs. $1.0 \%, p<0.001)$ were more frequent among foreigners. The difference between the percentages of admissions to ICU and emergency operations is greater in rural areas $(1.9 \%$ vs. $1.7 \%, p=0.066 ; 2.5 \%$ vs. $1.3 \%, p<$ $0.001)$. Natives accounted for more deaths in ED, ward, or ICU $(0.7 \%$ vs. $0.6 \%, p<0.001)$. However, there was no statistically significant difference between deaths in rural and urban areas $(0.8 \%$ vs. $0.8 \%, p<0.715)$. The length of stay in the ED for foreigners was longer than that for native patients (72 minutes vs. 69 minutes, $p<0.001$ ).

In rural areas, there were more serious outcomes than in urban areas, especially regarding emergency operations (Figure 2). When serious outcome was the dependent variable, the OR of foreign nationality was 1.412 with statistical significance (95\% CI, 1.336-1.492; $p<0.001$ ) (Table 3 ). Intentional injury $(\mathrm{OR}=3.911 ; 95 \% \mathrm{CI}, 3.787-4.040 ; p<$ $0.001)$ and no insurance $(\mathrm{OR}=1.354 ; 95 \% \mathrm{CI}, 1.314-1.394$; $p<0.001)$ were also statistically significant. Decreased consciousness (OR = 9.671; 95\% CI, 9.437-9.911; $p<0.001)$ and low blood pressure at ED presentation $(\mathrm{OR}=3.787 ; 95 \% \mathrm{CI}$, 3.654-3.926; $p<0.001$ ) showed high OR. A detailed agebased analysis is presented in Supplementary Table S1.

\section{Discussion}

We demonstrated that serious outcomes (ICU admission, emergency operation, or death) were more frequent in foreigners than native Koreans (3.8\% vs. $3.1 \%, p<0.001)$. In rural areas, the difference between serious outcomes for foreigners and natives was greater $(5.0 \%$ vs. $3.7 \%, p<0.001)$. The adjusted OR for foreigners for serious outcome was 1.412 (95\% CI, 1.336-1.492). ICU admission is the highest rated among three types of serious outcomes (ICU admission, $1.7 \%$ vs. $1.6 \%, p<0.001$; emergency operation, $1.7 \%$ vs. $1.0 \%, p<$ 0.001 ; death, $0.7 \%$ vs. $0.6 \%, p<0.001$ ). Although previous studies have mainly focused on mortality, our study was able to show differences between foreigners and natives for other serious outcomes, including ICU admissions and emergency operations. Furthermore, our study has the advantage in that it included foreigners who were not registered because we used actual emergency room visit data; hence, more realistic interpretations were possible. Unlike medical illnesses, injuries more often require visits to the emergency room; thus, our approach is less biased.

In our study, foreigners presented with more violencerelated and penetrating injuries than Koreans $(20.2 \%$ vs. $19.6 \%, 17.8 \%$ vs. $14.2 \%, p<0.001$ ) (Table 1, Figure 1). Several factors explain this. First, in Korea, these mechanisms are known to be associated with murder attempts, crime, 


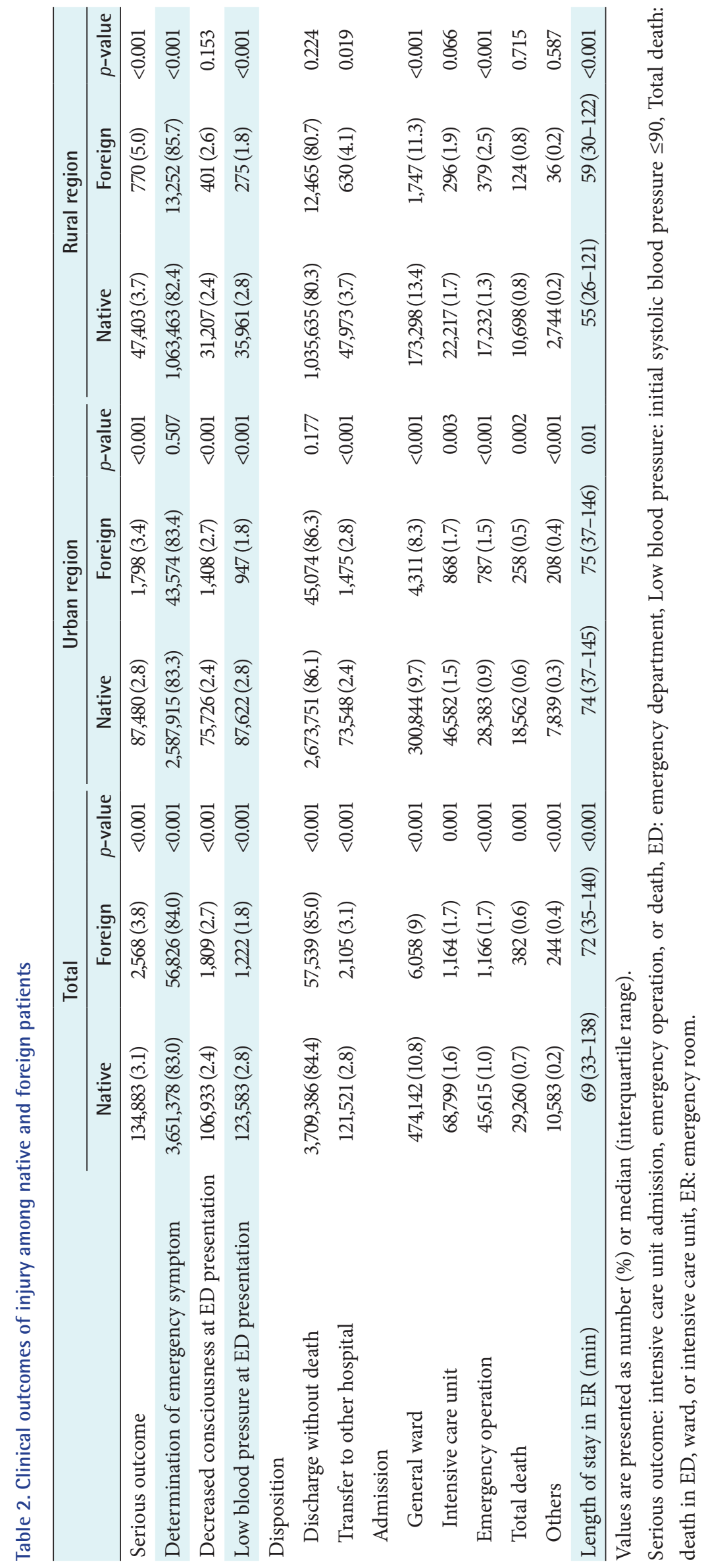


and violence [13]. As reported in the literature, murders and other crimes are more frequent among foreigners [6,1416]. Second, the lower socioeconomic status of foreigners, along with stress and culture shock, is also known to render them susceptible to violence $[6,10]$. In our study, decreased consciousness at ED presentation was more frequent among foreigners $(2.7 \%$ vs. $2.4 \%, p<0.001)$. The OR of decreased consciousness for serious outcomes was 9.671 (95\% CI, 9.437-9.911; $p<0.001)$. We do not know whether this is related to injury of the head or alcohol or drug abuse due to lack of data. Alcohol consumption is known to be associated with risky behavior [10]. Given the high level of violence as

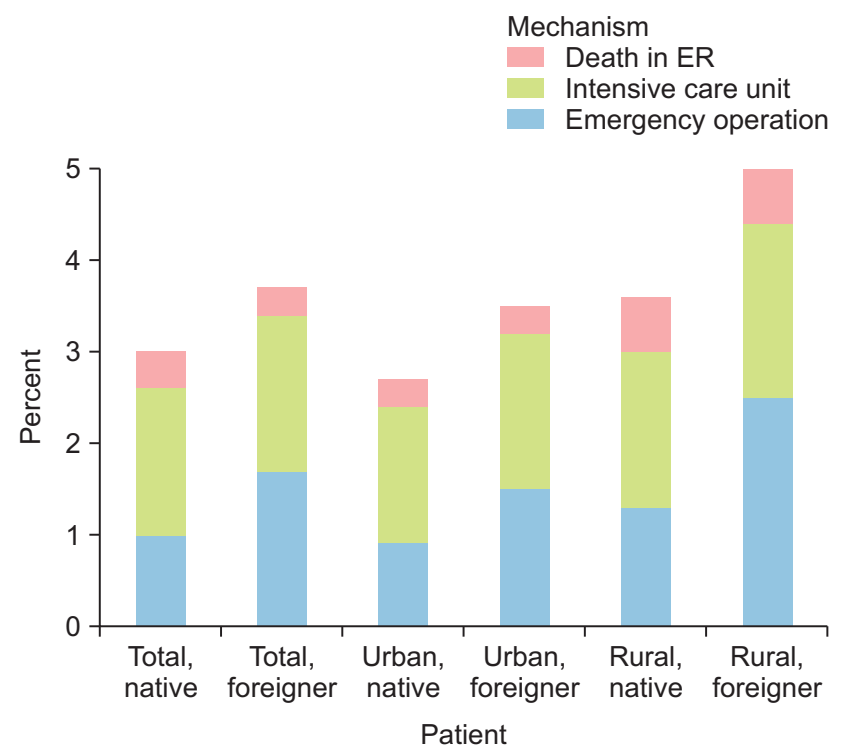

Figure 2. Serious outcomes for native and foreign patients by region. ER: emergency room. a cause of injury, the effect of alcohol needs to be evaluated later.

Foreigners had a higher rate of burn and machine-related injuries ( $3.6 \%$ vs. $3.2 \%, 3.6 \%$ vs. $1.0 \%, p<0.001$ ) (Table 1 , Figure 1). These two injuries are assumed to be associated with occupational risks [11]. In many countries, including South Korea, foreigners with unskilled, high-risk jobs are more likely to be injured $[6,10,11]$. There are several reasons why foreigners are engaged in high-risk jobs. Low socioeconomic status in foreigners is associated with a higher risk of work-related injury [8]. These foreigners are more likely to be reluctant to disclose work-associated risks and more fearful of losing their jobs $[11,17]$. Foreigners engaged in highrisk jobs often lack knowledge of safety regulations and are inadequately trained and supervised $[8,18,19]$. Language barriers also deepen the problem $[18,19]$.

Tiruneh et al. [8] found that ethnic minorities presented with more ICU admissions. However, the study did not uncover the reasons behind this observation [8]. In our study, admission to ICU $(1.7 \%$ vs. $1.6 \%, p<0.001)$ and the need for emergency operations ( $1.7 \%$ vs. $1.0 \%, p<0.001)$ are more frequent among foreigners. However, there were more deaths in EDs, wards, or ICUs among natives $(0.7 \%$ vs. $0.6 \%, p<$ 0.001 ). The determination of emergency symptoms, which reflects the severity at the time of the visit to the emergency room, was higher among foreigners ( $84 \%$ vs. $83 \%, p<0.001$ ) (Table 2). It can be assumed that injuries to foreigners are more severe. In many studies conducted in countries with a long history of immigration, mortality rates vary widely depending on the age group, sex, and country-of-origin of the immigrant $[2,14,20-22]$. In our study, young adults were

Table 3. Adjusted odds ratios for serious outcome in foreign patients with injuries

\begin{tabular}{|c|c|c|c|}
\hline & Adjusted odds ratio & 95\% confidence interval & $p$-value \\
\hline Foreign nationality & 1.412 & $1.336-1.492$ & $<0.001$ \\
\hline Intentional injury & 3.911 & $3.787-4.040$ & $<0.001$ \\
\hline No insurance & 1.354 & $1.314-1.394$ & $<0.001$ \\
\hline Urban area & 1.065 & $1.049-1.082$ & $<0.001$ \\
\hline Age & 1.007 & $1.007-1.007$ & $<0.001$ \\
\hline Male sex & 1.967 & $1.936-1.999$ & $<0.001$ \\
\hline Determination of emergency symptom & 2.176 & $2.088-2.267$ & $<0.001$ \\
\hline Decreased consciousness & 9.671 & $9.437-9.911$ & $<0.001$ \\
\hline Low blood pressure at ED presentation & 3.787 & $3.654-3.926$ & $<0.001$ \\
\hline Transfer to other hospital & 1.786 & $1.747-1.825$ & $<0.001$ \\
\hline Length of stay in ER & 1.000 & $1.000-1.000$ & $<0.001$ \\
\hline
\end{tabular}

Serious outcome: intensive care unit admission, emergency operation, or death, Low blood pressure: initial systolic blood pressure $\leq 90$, ED: emergency department, ER: emergency room. 
overrepresented among foreigners admitted to emergency rooms (Figure 1). Injuries requiring surgery or ICU admission are more common in foreigners, but the mortality rate is thought to be lower than that of native Koreans because the injuries occur at relatively younger ages in foreigners.

In our study, disparities in outcome were particularly large in rural areas compared to urban areas among both natives and foreigners (Table 2, Figure 2). Foreigners seem to be more disadvantaged than natives in rural areas. Transfer to other hospitals suggests transfer to a higher treatment facility. There were more transfers (4.1\% vs. $2.8 \%)$ (Table 2$)$ in rural areas than in urban areas. In rural areas, it is thought that access to medical care is low, especially access to higher treatment facilities. Regarding insurance possession, foreigners were more likely to have no insurance $(32.0 \%$ vs. $3.1 \%, p$ $<0.001)$. Since it is not difficult to meet the requirements for national health insurance, this injured foreigners group may include undocumented foreigners. Unlike previous studies, our study analyzed emergency room visit data, which may provide a more sensitive indicator of unregistered foreigners. In Table 3, the OR of foreign nationalities for serious outcomes was 1.412, and that of patients with no insurance was 1.354 .

This study had several limitations. The NEDIS does not include data from low-level EDs. Therefore, it does not include all injuries in South Korea. There is a possibility that the actual number of injuries was underestimated. Due to the limitations of the data, it was not possible to investigate socioeconomic status, alcohol use, and severity scores, such as the injury severity score. Hence, the results of our study should be interpreted with consideration of the limitation that there has been no adjustment for these factors; thus, over-interpretation may be avoided. The study data are casebased, so in cases of transfer, duplicate counts may have occurred.

In this study, we demonstrated that there were more serious outcomes among foreigners, and their disadvantage might be greater in rural areas in comparison to urban areas. Apart from medical factors, foreign nationality itself and lack of insurance could adversely affect medical outcomes. Our study has the advantage that it might have included unregistered foreigners because it used actual emergency room visit data. This study highlighted health inequalities between injured foreigners and native Koreans, and it may contribute to developing appropriate policies and preventive activities to reduce these disparities.

\section{Conflict of Interest}

No potential conflict of interest relevant to this article was reported.

\section{Acknowledgments}

This study was performed using data from the $\mathrm{Na}$ tional Emergency Department Information System (No N20170821111) of the National Emergency Medical Center.

\section{ORCID}

Jin Young Kang (https://orcid.org/0000-0001-8127-2048)

Jinhee Kwon (https://orcid.org/0000-0002-4640-7266)

Chang Hwan Sohn (https://orcid.org/0000-0001-9747-0196)

Youn-Jung Kim (https://orcid.org/0000-0003-1385-5836)

Hyo Won Lim (https://orcid.org/0000-0002-2385-3036)

Seung Joon Lee (https://orcid.org/0000-0003-1655-0878)

Won Young Kim (https://orcid.org/0000-0002-6904-5966)

Namkug Kim (https://orcid.org/0000-0002-3438-2217)

Dong-Woo Seo (https://orcid.org/0000-0001-8104-0247)

\section{References}

1. International Organization for Migration. World migration report 2010: the future of migration: building capacities for change. Geneva, Switzerland: International Organization for Migration; 2010.

2. Moncho J, Pereyra-Zamora P, Nolasco A, Tamayo-Fonseca N, Melchor I, Macia L. Trends and disparities in mortality among spanish-born and foreign-born populations residing in Spain, 1999-2008. J Immigr Minor Health 2015;17(5):1374-84.

3. Korean Statistical Information Service. Population census [Internet]. Daejeon, Korea: Statistics Korea; c2019 [cited at 2020 Jan 23]. Available from: http://kosis.kr/ eng/.

4. Carballo M, Nerukar A. Migration, refugees, and health risks. Emerg Infect Dis 2001;7(3 Suppl):556-60.

5. Singh GK, Siahpush M. All-cause and cause-specific mortality of immigrants and native born in the United States. Am J Public Health 2001;91(3):392-9.

6. Stirbu I, Kunst AE, Bos V, van Beeck EF. Injury mortality among ethnic minority groups in the Netherlands. J Epidemiol Community Health 2006;60(3):249-55.

7. Karimi N, Beiki O, Mohammadi R. Risk of fatal unintentional injuries in children by migration status: a na- 
tionwide cohort study with 46 years' follow-up. Inj Prev 2015;21(e1):e80-7.

8. Tiruneh A, Siman-Tov M, Radomislensky I, Itg, Peleg K. Characteristics and circumstances of injuries vary with ethnicity of different population groups living in the same country. Ethn Health 2017;22(1):49-64.

9. Savitsky B, Aharonson-Daniel L, Giveon A, Group TI, Peleg K. Variability in pediatric injury patterns by age and ethnic groups in Israel. Ethn Health 2007;12(2):12939.

10. Norredam M, Olsbjerg M, Petersen JH, Laursen B, Krasnik A. Are there differences in injury mortality among refugees and immigrants compared with native-born? Inj Prev 2013;19(2):100-5.

11. Cha S, Cho Y. Fatal and non-fatal occupational injuries and diseases among migrant and native workers in South Korea. Am J Ind Med 2014;57(9):1043-52.

12. National Emergency Medical Center. Statistical yearbook of the National Emergency Department Information System 2016 [Internet]. Seoul, Korea: National Emergency Medical Center; c2019 [cited at 2020 Jan 23]. Available from: https://www.e-gen.or.kr/nemc/statistics_annual_report.do?brdclscd $=02$.

13. Jeon H, Kang GH, Jang YS, Choi JT, Kim JH, Lee BJ, et al. Evaluation of emergency care for foreign patients in Korea. J Korean Soc Emerg Med 2011;22(6):735-42.

14. Bos V, Kunst AE, Keij-Deerenberg IM, Garssen J, Mackenbach JP. Ethnic inequalities in age- and causespecific mortality in The Netherlands. Int J Epidemiol
2004;33(5):1112-9.

15. Sampson RJ, Morenoff JD, Raudenbush S. Social anatomy of racial and ethnic disparities in violence. Am J Public Health 2005;95(2):224-32.

16. Demetriades D, Murray J, Sinz B, Myles D, Chan L, Sathyaragiswaran L, et al. Epidemiology of major trauma and trauma deaths in Los Angeles County. J Am Coll Surg 1998;187(4):373-83.

17. Centers for Disease Control and Prevention (CDC). Work-related injury deaths among Hispanics: United States, 1992-2006. MMWR Morb Mortal Wkly Rep 2008;57(22):597-600.

18. Orrenius PM, Zavodny M. Do immigrants work in riskier jobs? Demography 2009;46(3):535-51.

19. Smith PM, Chen C, Mustard C. Differential risk of employment in more physically demanding jobs among a recent cohort of immigrants to Canada. Inj Prev 2009;15(4):252-8.

20. Sundquist J, Johansson SE. The influence of country of birth on mortality from all causes and cardiovascular disease in Sweden 1979-1993. Int J Epidemiol 1997;26(2):279-87.

21. Wild S, McKeigue P. Cross sectional analysis of mortality by country of birth in England and Wales, 1970-92. BMJ 1997;314(7082):705-10.

22. Stirbu I, Kunst AE, Bos V, Mackenbach JP. Differences in avoidable mortality between migrants and the native Dutch in The Netherlands. BMC Public Health 2006;6:78. 